\title{
Effect of cow's milk with different PUFA n-6: n-3 ratios on performance, serum lipid profile, and blood parameters of grower gilts.
}

Authors: Leriana Garcia Reis ${ }^{1}$, Thiago Henrique da Silva ${ }^{1}$, Márcia Saladini Vieira Salles ${ }^{2}$, André Furugen Cesar Andrade ${ }^{3}$, Simone Maria Massami Kitamura Martins ${ }^{1}$, Paula Lumy Takeuchi $^{4}$,Ana Maria Centola Vidal ${ }^{5}$, Arlindo Saran Netto ${ }^{1}$

Running head: Milk with an altered lipid profile without impair the health

${ }^{1}$ Department of Animal Science, School of Animal Science and Food Engineering, University of São Paulo, Rua Duque de Caxias Norte, 225, 13635-900, Pirassununga, SP, Brazil.

${ }^{2}$ Animal Science Institute, Avenida Bandeirantes, 2419, Ribeirão Preto 14030-640, Brazil

${ }^{3}$ Department of Animal Reproduction, School of Veterinary and Animal Science, University of São Paulo, Avenida Duque de Caxias Norte, 225, Pirassununga 13635-900, Brazil.

${ }^{4}$ Department of Internal Medicine, School of Medicine of Ribeirão Preto, University of São Paulo, Avenida Bandeirantes, 3900, Ribeirão Preto, 14049-900, Brazil.

${ }^{5}$ Department of Veterinary Medicine, School of Animal Science and Food Engineering, University of São Paulo, Rua Duque de Caxias Norte, 225, 13635-900, Pirassununga, SP, Brazil.

Corresponding author: Arlindo Saran Netto. Phone number: +55 19 35654000/+55 19 35654039/+55 19 997270373. Email: saranetto@usp.br

Key words: Fatty acid metabolism, health, hemogram, polyunsaturated fatty acids, supplementation, vegetable oil. 


\section{ABBREVIATIONS}

ADFI, average daily feed intake; ADG, average daily gain; EPA, eicosapentaenoic acid; FCR, feed conversion ratio; HDL, high-density lipoproteins; LTs, leukotrienes; LDL, lowdensity lipoproteins; $\mathrm{MCH}$, mean corpuscular hemoglobin; PUFA, polyunsaturated fatty acids; RBC, red blood cells; SCD, stearoyl-CoA desaturase; SFA, saturated fatty acids; USFA, unsaturated fatty acids; VLDL, very-low-density lipoprotein.

(1)

\section{ABSTRACT}

The concern with human health has increased the interest in producing foods enriched with polyunsaturated fatty acids (PUFA), directly or naturally by inclusion in the animals' diet. The positive effects such as antithrombotic, anti-inflammatory, and hypolipidemic have been observed in pigs and rats, used as human models for study. The present study evaluated the effect of cow's milk with different lipid profiles on performance, serum fatty acid profile, biochemical analysis, and a complete blood count of gilts used as a human model. At 34 days, thirty gilts were equally distributed in three treatments. Experimental treatments were milk from cows without the oil supplementation (C), milk from cows fed an enriched diet with linseed oil (n-3), and milk from cows fed an enriched diet with soybean oil (n-6). Milk supplementation was performed until the age of 190 days, provided once in the morning. The n-3 and n-6 milk reduced the concentration of myristic acid in the blood and increased the leukocytes. Milk enriched with n-3 compared to n- 6 reduced stearic acid. In conclusion, milk with a better PUFA profile can reduce saturated fatty acids in the blood and alter the concentration of cells in the defense system. 
The consumption of cow's milk and its derivatives in human nutrition has been reduced or even replaced by other beverages of vegetable origin due to the lipid profile [1] and also due to the occurrence of lactose intolerance and some proteins [2].

It is known that the composition of fatty acids in cow's milk can be changed and is highly influenced by the nature of the forage consumed, supplementation with vegetable or oilseed oils, and even vitamin $\mathrm{E}$ and this change can be verified in a few hours [3,4]. Researchers have intensified studies in modifying the lipid profile in milk and meat [5,6]. More than 400 fatty acids compounded milk fat, and among them, saturated fatty acids (SFA) are in greater concentration. Excessive consumption of SFA has generated discussions because it is associated with an increased risk of developing several diseases, in addition to causing an increase in highdensity lipoproteins (HDL) and low-density lipoproteins (LDL) cholesterol [7-9]. Research has been carried out to include different sources of unsaturated fatty acids (USFA), among them mainly polyunsaturated fatty acids (PUFA), in the diet of cows, focusing on improving the composition of milk fat and nutraceutical properties for human consumption [10]. High n-3 PUFA content and low n-6/n-3 PUFA ratio are more beneficial to human health, which n-3 and n-6 polyunsaturated fatty acids and their proportions are correlated with human diseases [11].

According to [12], the inclusion of canola oil in dairy cow diets can reduce milk SFA and improved omega-3. Results similar were obtained by [13] showed alteration on milk fatty acids profile after supplementing dairy cows with linseed and soybean oil, resulting in improved saturated/unsaturated fatty acid ratio and higher content of omega-3, and a more desirable omega-6/omega-3 ratio.

Milk enriched with PUFA showed a reduction in the concentration of LDL in the blood of rats [14], and in gilts supplemented with cow's milk naturally enriched with n-3 and n-6 from 34 days of age until the end of lactation also showed a reduction in LDL for the n-3 and n-6 treatments and improve the performance of weaned piglets [15]. However, we did not find studies evaluating the effects of providing PUFA-enriched milk on the development of pigs, considering the pig as an animal model for humans. Several factors make some studies in humans unfeasible, such as the limitations of invasive procedures and the myriad of ethical 
issues, in addition to animal models being essential and relevant to support epidemiological studies [16]. In anatomy, neurobiology, cardiac vasculature, gastrointestinal tract, and genome, pigs are more human-like than mice and are currently considered adequate biomedical models [17]. Thus, the present study aimed to evaluate the supplementation of cow's milk naturally enriched with n-3 and n-6 polyunsaturated fatty acids on swine's health during the growing through growth performance, blood fatty acid profile, blood chemical variables, and complete blood counts.

\section{MATERIAL AND METHODS}

All activities performed in this study were reviewed and approved by the Animal Care Committee of the School of Animal Science and Food Engineering, University of Sao Paulo (\#4939070317).

\section{Animals, facilities, and treatment allocation}

Thirty hybrid gilts (Landrace x Large White) were evaluated from 34 to 190 days old and were randomly allocated into three groups: $\operatorname{control}(\mathbf{C}, \mathrm{n}=10)$, basal diet + milk from cows without the oil supplementation, omega-3 $(\mathbf{n}-\mathbf{3}, \mathbf{n}=10)$, basal diet + milk from cows fed an enriched diet with linseed oil, and omega-6 $(\mathbf{n - 6}, \mathrm{n}=10)$, basal diet + milk from cows fed an enriched diet with soybean oil.

At 34 days of age and initially weighing $9.59 \pm 1.28 \mathrm{~kg}$, the gilts were housed individually in pens (from 34 to 76 days, pre-initial and initial phase with $0.75 \mathrm{~m}^{2} /$ animal; subsequently from 77 to 190 days old, grower-finisher phase until replacement phase, with 2.06 $\mathrm{m}^{2} /$ gilt). The gilts were fed ad libitum twice a day (at 07:00 am and 1:00 pm) during the grower phase (130 days). After this period, the feed intake was adjusted according to [18]. The diets were based on corn and soybean feedstuffs and did not contain any oil as an ingredient (Table 1). All animals received ad libitum water. 
Table 1. Composition of pre-initial, initial, growth and termination diets, specific to each physiological phase of swine females

\begin{tabular}{lccccccc}
\hline Item & Pre-initial & Initial & Grower & Finisher & Replacement & Gestation & Lactation \\
\hline Ingredients, g.kg-1 & & & & & & & \\
Ground corn & 399.0 & 649.0 & 699.0 & 739.0 & 644.4 & 594.0 & 587.8 \\
Soybean meal & 200.0 & 300.0 & 280.0 & 240.0 & 240.8 & 140.0 & 265.1 \\
Wheat bran & - & - & - & - & 86.5 & 240.0 & - \\
UNIMIX $^{a}$ & 400.0 & 50.0 & 20.0 & 20.0 & 25.0 & 25.0 & 30.0 \\
L-lysine & - & - & - & - & - & - & 10.0 \\
DL-methionine & - & - & - & - & - & - & 2.0 \\
Sugar & - & - & - & - & - & - & 100.0 \\
Calcitic limestone & - & - & - & - & 2.3 & - & 4.1 \\
Mycofix & 1.0 & 1.0 & 1.0 & 1.0 & 1.0 & 1.0 & 1.0 \\
Chemical composition & & & & & & & \\
Dry matter, \% & 83.41 & 87.92 & 87.07 & 88.93 & 88.12 & 89.42 & 88.25 \\
Ashes, \% & 6.69 & 5.43 & 4.80 & 3.70 & 4.54 & 5.23 & 5.62 \\
Crude energy, cal.g- ${ }^{-1}$ & 4347.0 & 4393.0 & 4419.0 & 4465.0 & 4411.5 & 4360.0 & 4376.0 \\
Ether extract, \% & 4.14 & 1.71 & 2.41 & 1.71 & 1.37 & 1.40 & 1.56 \\
Crude fiber, \% & 4.54 & 4.32 & 4.30 & 4.07 & 3.01 & 5.23 & 5.28 \\
Crude protein, \% & 18.04 & 21.21 & 18.07 & 20.46 & 19.04 & 17.59 & 19.99 \\
Calcium, \% & 0.90 & 0.80 & 0.63 & 0.51 & 0.82 & 0.81 & 0.94 \\
Phosphorus, \% & 0.69 & 0.53 & 0.41 & 0.37 & 0.38 & 0.46 & 0.43 \\
\hline
\end{tabular}

aThe premix used in each phase was based on Rostagno et al. [18] 

128 days), $400 \mathrm{~mL}$ (from 129 to 174 days), and $500 \mathrm{~mL}$ (175 to 190 days) of cow's milk. The enriched milk provided to the gilts in this current study was obtained from the study carried out by [13] using Holstein cows. Briefly, the cows were supplemented or not with 2,5\% (dry matter basis) of linseed or soybean oil, sources of n-3 and n-6, respectively. The effects of these vegetable oils' inclusion on the lipid fraction profile of dairy cows' milk are presented in Table

Table 2. The lipid fraction of enriched cow's milk

\begin{tabular}{|c|c|c|c|c|c|c|c|}
\hline \multirow{2}{*}{ Fatty acid profile ${ }^{a}$, g. $100 \mathrm{~g}^{-1}$} & \multicolumn{3}{|c|}{ Diets $^{b}$} & \multirow{2}{*}{$\mathrm{SEM}^{\mathrm{c}}$} & \multicolumn{3}{|c|}{$P^{d}$} \\
\hline & $\mathrm{CON}$ & LIN & SOY & & Treatment & $\mathrm{C} 1$ & $\mathrm{C} 2$ \\
\hline$\Sigma$ SFA & 66.887 & 56.605 & 56.524 & 1.441 & $<0.01$ & $<0.01$ & 0.969 \\
\hline$\Sigma$ USFA & 33.051 & 43.346 & 43.394 & 1.438 & $<0.01$ & $<0.01$ & 0.986 \\
\hline SFA/USFA & 2.121 & 1.364 & 1.341 & 0.107 & $<0.01$ & $<0.01$ & $<0.01$ \\
\hline$\Sigma$ MUFA & 29.583 & 39.470 & 39.551 & 1.301 & $<0.01$ & $<0.01$ & 0.966 \\
\hline$\Sigma$ PUFA & 3.570 & 3.979 & 3.935 & 0.275 & 0.199 & 0.076 & 0.860 \\
\hline$\Sigma \mathrm{n}-3$ & 0.324 & 1.022 & 0.360 & 0.029 & $<0.01$ & $<0.01$ & $<0.01$ \\
\hline$\Sigma \mathrm{n}-6$ & 2.483 & 2.252 & 2.880 & 0.208 & 0.004 & 0.589 & 0.001 \\
\hline$n-6 / n-3$ & 7.919 & 2.724 & 8.263 & 0.504 & $<0.01$ & $<0.01$ & $<0.01$ \\
\hline Cholesterol, g.100 mL-1 & 9.942 & 8.741 & 10.053 & 1.649 & 0.174 & 0.403 & 0.097 \\
\hline
\end{tabular}

fatty acids; $\Sigma$ n-3 $=\Sigma$ omega-3 fatty acids; $\Sigma$ n-6 $=\Sigma$ omega- 6 fatty acids; $n-6 / n-3=\Sigma$ omega$6 / \Sigma$ omega-3.

${ }^{b}$ Cows fed with a control diet (CON), supplemented with linseed oil (LIN) or soybean oil

97 (SOY).

${ }^{\mathrm{c}} \mathrm{SEM}$, standard error of the means.

${ }^{\mathrm{d}} \mathrm{C} 1$, contrast between CON vs LIN+SOY; C2, contrast between LIN vs SOY.

Data collection 
Growth

Body weight (BW) was assessed using a digital scale (Toledo ${ }^{\circledR}$, model MGR-3000, São

Bernardo do Campo, SP), consisting of initial (from 34 to 76), grower (from 77 to 112), and

finisher (from 113 to 190) phases. Additionally, average daily feed intake (ADFI), and from calculated.

\section{Blood sampling and analysis}

Whole blood, serum, and plasma were collected by jugular venipuncture using a $1.2 \times$

blood and serum were collected into $2 \mathrm{~mL}$ tubes with a clot activator, and plasma into $2 \mathrm{~mL}$ Americana, SP, Brazil).

After collection, all tubes were immediately submitted to the laboratory (Diagnostic Laboratory for Clinical Analysis, Pirassununga, Brazil). The complete blood count was evaluated by Sysmex ${ }^{\circledR}$ equipment (model XS-800i, Kobe, Japan). The serum sample was quantified by gas chromatography [20]. The plasma sample was analyzed for total cholesterol, HDL, total protein, and serum urea using enzyme kits (VIDA Biotecnologia ${ }^{\circledR}$, Minas Gerais, Brazil). LDL and triacylglycerol were analyzed using enzyme kits (LABTEST ${ }^{\circledR}$, Minas Gerais, Brazil). The very-low-density lipoprotein (VLDL) concentration was determined indirectly by the following equation [21]: VLDL cholestrol $\left(\frac{m g}{d l}\right)=$ triglyceride concentration $\div 5$. All analyses were according to the manufacturer's instructions.

Statistical Analyses

All statistical analyses were performed using SAS 9.4 (SAS Inst. Inc., Cary, NC). The data were analyzed in a completely randomized design, and the animal was considered an 
131 the residues was verified by the Shapiro-Wilk test (UNIVARIATE procedure of SAS), and information with student residues greater than +3 or less than -3 was excluded from the analyzes. The Levene test compared the homogeneity of the variances. Variables with a continuous distribution such as body weight, average daily gain, average daily feed intake, feed conversion rate, complete blood counts, biochemical parameters, and fatty acids profile of blood were analyzed using the MIXED procedure of SAS. When the time factor was present, repeated measures models were fitted by multiple mixed linear models using the MIXED procedure of SAS. The model included: the fixed effects of treatment, time and their interaction, and the random effect of the animal. The experimental unit was the gilt. The SLICE option using the LSMEANS/PDIFF command was used to explore the interactions between treatment and day of data collection. The Kenward-Roger method was used to correct the degree of freedom of the denominator for the F test. The covariance structure was determined based on the lowest Akaike information criteria value. The treatments were analyzed using two orthogonal contrasts: contrast $1(\mathrm{C} 1)$ control group vs. n-3 + n-6 groups, and contrast $2(\mathrm{C} 2)$ n-3 group vs. n- 6 group. Significance level was set at $\mathrm{P}<0.05$ and tendency towards significance at $0.05<\mathrm{P}<0.10$.

\section{RESULTS}

All gilts consumed their supplementation successfully so that the milk remains were not significant.

\section{Gilts' performance}

There was no difference in the treatment $\mathrm{x}$ time interaction on performance. Females supplemented with n-3 and n-6 had similar growth performance between themselves, and in comparison, to those of the control groups (see S1 Fig). Only time effect was observed for all these variables $(\mathrm{P}<0.001$, Table 3$)$. 
157 Table 3. Growth performance of gilts from 34 to 190 days of age, for treatments C, n-3 and n-6

\begin{tabular}{|c|c|c|c|c|c|c|c|c|c|}
\hline \multirow[b]{2}{*}{ Item $^{\mathrm{a}}$} & \multicolumn{3}{|c|}{ Treatments $^{\mathrm{b}}$} & \multirow{2}{*}{$\mathrm{SEM}^{\mathrm{c}}$} & \multicolumn{5}{|c|}{ P-value } \\
\hline & Control & $n-3$ & $n-6$ & & Treatment & Time & Treat*Time & $\mathrm{C}^{\mathrm{d}}$ & $C 2^{\mathrm{d}}$ \\
\hline $\mathrm{BW}, \mathrm{kg}$ & 67.570 & 67.540 & 66.750 & 2.654 & 0.942 & $<0.0001$ & 0.929 & 0.947 & 0.915 \\
\hline ADG, kg.dia ${ }^{-1}$ & 0.754 & 0.750 & 0.734 & 0.044 & 0.864 & $<0.0001$ & 0.967 & 0.760 & 0.729 \\
\hline ADFI, kg.dia ${ }^{-1}$ & 2.348 & 2.356 & 2.328 & 0.046 & 0.846 & $<0.0001$ & 0.949 & 0.951 & 0.812 \\
\hline $\mathrm{FC}$ ratio, $\mathrm{kg} \cdot \mathrm{kg}^{-1}$ & 3.138 & 3.147 & 2.990 & 0.063 & 0.870 & $<0.0001$ & 0.948 & 0.598 & 0.323 \\
\hline
\end{tabular}

158 a BW: body weight; ADG: average daily gain; ADFI: average daily feed intake; FC ratio: feed:gain ratio.

159 'Sows fed with a Control milk (Control), supplemented with cow's milk enriched with n-3 or n-6.

160 'SEM, standard error of the mean.

$161{ }^{\mathrm{d}} \mathrm{C} 1$, contrast Control vs n-3+n-6; C2, contrast n-3 vs n-6. 
Fatty Acids Profile in Gilts Serum

At 77 days old, the control group had greater myristic acid concentration than those that received enriched cow's milk ( $n-3$ and $n-6 P=0.062$, Fig 1 and $S 2$ fig). At 132 days old, the $n-3$ gilts had an increased $\gamma$-linolenic acid concentration than other groups $(\mathrm{P}=0.079$, Fig 2$)$. The control gilts group had raised myristic acid concentration compared to the females of other groups $(\mathrm{P}=0.031$, Table 4). Besides, the $\mathrm{n}-3$ gilts group had a small SFA concentration $(\mathrm{P}=0.090)$ and ratio SFA: USFA, $(\mathrm{P}=0.097)$ and greater USFA than those of control and $\mathrm{n}-6$ groups $(P=0.090$, Table 4). Also, the $n-3$ female groups had lower stearic acid concentration $(\mathrm{P}=0.002$, Table 4 and $\mathrm{S} 2 \mathrm{fig})$ and greater oleic acid concentration than those of the $\mathrm{n}-6$ group $(\mathrm{P}=0.081$, Table 4$)$. The other fatty acids were similar among groups $(\mathrm{P}>0.05$, Table 4$)$.

Fig 1. Tendency to increase myristic acid for Control at 77 days of age of gilts S2 Fig. Myristic and stearic acid of females from 34 to 190 days old Fig 2. $\gamma$-linolenic tends to have a higher concentration in n-3 treatment at 132 days of age of gilts 
Table 4. Serum quantitative fatty acid profile for treatments Control, n-3 and n-6 of females supplemented from 34 to 190 days of age

\begin{tabular}{|c|c|c|c|c|c|c|c|c|c|}
\hline \multirow{2}{*}{ Fatty acids ${ }^{\mathrm{a}}, \mu \mathrm{g} \cdot \mathrm{ml}^{-1}$} & \multicolumn{3}{|c|}{ Treatments $^{\mathrm{b}}$} & \multirow{2}{*}{$\mathrm{SEM}^{\mathrm{c}}$} & \multicolumn{5}{|c|}{ P-value } \\
\hline & Control & $n-3$ & $n-6$ & & Treatment & Time & Treat*Time & $\mathrm{C} 1^{\mathrm{d}}$ & $\mathrm{C} 2^{\mathrm{d}}$ \\
\hline Myristic, C14:0 & 0.869 & 0.669 & 0.653 & 0.070 & 0.087 & $<0.0001$ & 0.062 & 0.031 & 0.875 \\
\hline Palmitic, C16:0 & 17.730 & 17.800 & 17.490 & 0.713 & 0.950 & 0.0465 & 0.541 & 0.925 & 0.766 \\
\hline Stearic, C18:0 & 12.430 & 11.830 & 13.560 & 0.304 & 0.006 & $<0.0001$ & 0.408 & 0.497 & 0.002 \\
\hline Elaidic, C18:1t n-9 & 0.382 & 0.293 & 0.379 & 0.079 & 0.686 & 0.0024 & 0.174 & 0.652 & 0.470 \\
\hline Palmitoleic, C16:1c9 & 1.136 & 1.167 & 1.117 & 0.097 & 0.936 & 0.0016 & 0.937 & 0.961 & 0.721 \\
\hline Oleic, C18:1c9 & 23.330 & 24.050 & 22.130 & 0.714 & 0.200 & 0.0028 & 0.684 & 0.790 & 0.081 \\
\hline Linoleic, C18:2 n-6 & 28.390 & 29.770 & 28.670 & 0.545 & 0.225 & 0.0001 & 0.708 & 0.242 & 0.190 \\
\hline Dihomo- $\gamma$-linolenic, C20:3 n-6 & 0.695 & 0.688 & 0.660 & 0.045 & 0.852 & $<0.0001$ & 0.637 & 0.714 & 0.679 \\
\hline ARA, C20:4 n-6 & 11.240 & 11.000 & 12.410 & 0.589 & 0.239 & $<0.0001$ & 0.587 & 0.534 & 0.121 \\
\hline$\gamma$-Linolenic, C18:3 n-6 & 0.506 & 0.567 & 0.531 & 0.028 & 0.336 & $<0.0001$ & 0.079 & 0.232 & 0.381 \\
\hline$\alpha$-Linolenic, C18:3 n-3 & 0.563 & 0.618 & 0.588 & 0.026 & 0.361 & $<0.0001$ & 0.326 & 0.232 & 0.431 \\
\hline EPA, C20:5 n-3 & 0.219 & 0.343 & 0.461 & 0.096 & 0.239 & 0.1157 & 0.280 & 0.143 & 0.397 \\
\hline DHA, C22:6 n-3 & 1.203 & 1.184 & 1.371 & 0.112 & 0.459 & $<0.0001$ & 0.300 & 0.617 & 0.260 \\
\hline Saturated & 31.410 & 30.370 & 31.150 & 0.339 & 0.090 & $<0.0001$ & 0.450 & 0.124 & 0.106 \\
\hline Unsaturated & 68.590 & 69.630 & 68.850 & 0.323 & 0.090 & $<0.0001$ & 0.450 & 0.124 & 0.106 \\
\hline SFA/USFA & 0.458 & 0.438 & 0.453 & 0.006 & 0.097 & $<0.0001$ & 0.472 & 0.132 & 0.110 \\
\hline Monoutansaturated & 25.240 & 25.430 & 24.040 & 0.675 & 0.312 & 0.0005 & 0.234 & 0.547 & 0.164 \\
\hline Polyunsaturated & 43.340 & 44.200 & 44.880 & 0.817 & 0.438 & 0.2194 & 0.229 & 0.255 & 0.563 \\
\hline
\end{tabular}




\begin{tabular}{lccccccccc} 
Total n-3 & 2.002 & 2.154 & 2.384 & 0.142 & 0.197 & $<0.0001$ & 0.296 & 0.152 & 0.262 \\
Total n-6 & 41.350 & 42.050 & 42.480 & 0.775 & 0.596 & 0.0247 & 0.458 & 0.354 & 0.694 \\
n-6/n-3 & 27.271 & 26.347 & 25.528 & 1.112 & 0.559 & $<0.0001$ & 0.459 & 0.341 & 0.612 \\
ARA/EPA & 59.854 & 57.438 & 46.762 & 6.832 & 0.379 & 0.0043 & 0.174 & 0.368 & 0.285 \\
\hline
\end{tabular}

ARA/EPA

aEPA: eicosapentaenoic acid; DHA: docosahexaenoic acid; ARA: arachidonic acid; USFA/SFA: unsaturated/saturated fatty acids; Total n-3: sum of n-3 fatty acids; Total n-6: sum of n-6 fatty acids; n-6/n-3, ratio of total n-6 to total n-3 fatty acids; ARA/EPA: ratio of arachidonic acid to eicosapentaenoic acid.

178 bSows fed with a Control milk (Control), supplemented with cow's milk enriched with n-3 or n-6

180 cSEM, standard error of the mean.

$181{ }^{\mathrm{d}} \mathrm{C} 1$, contrast Control vs n-3+n-6; C2, contrast n-3 vs n-6. 
At 77 days old, the n-6 gilts group had greater LDL than those of other groups

$184(\mathrm{P}=0.083$, Fig 3$)$. Besides, these females increased HDL compared to the $\mathrm{n}-3$ group $(\mathrm{P}=0.063$,

185 Table 5). The other biochemical parameters were similar among females of the control group

186 and those supplemented with enriched cow's milk $(\mathrm{P}>0.05)$.

187 Fig 3. Behavior of the LDL curve at 77 days of gilts 
Table 5. Biochemical parameters of the serum of gilts from 34 to 190 days of age

\begin{tabular}{|c|c|c|c|c|c|c|c|c|c|}
\hline \multirow{2}{*}{ Biochemical parameters } & \multicolumn{3}{|c|}{ Treatments $^{a}$} & \multirow{2}{*}{$\mathrm{SEM}^{b}$} & \multicolumn{5}{|c|}{ P-value } \\
\hline & Control & $\mathrm{n}-3$ & $\mathrm{n}-6$ & & Treatment & Time & Treat*Time & $\mathrm{C} 1^{\mathrm{c}}$ & $\mathrm{C} 2^{\mathrm{c}}$ \\
\hline Urea, $m g . \mathrm{dL}^{-1}$ & 23.590 & 24.370 & 24.380 & 1.060 & 0.833 & $<0.0001$ & 0.851 & 0.722 & 0.978 \\
\hline Total protein, g.dL-1 & 5.760 & 5.720 & 5.810 & 0.070 & 0.661 & $<0.0001$ & 0.332 & 0.959 & 0.634 \\
\hline Total cholesterol, mg.dL ${ }^{-1}$ & 79.180 & 77.110 & 79.350 & 2.290 & 0.747 & $<0.0001$ & 0.181 & 0.687 & 0.490 \\
\hline Glucose, mg.dL ${ }^{-1}$ & 90.330 & 85.510 & 86.490 & 1.620 & 0.101 & $<0.0001$ & 0.198 & 0.133 & 0.768 \\
\hline Triglycerides, mg.dL $\mathrm{dL}^{-1}$ & 35.890 & 37.300 & 32.490 & 2.860 & 0.501 & $<0.0001$ & 0.517 & 0.751 & 0.275 \\
\hline $\mathrm{HDL}, \mathrm{mg} \cdot \mathrm{dL}^{-1}$ & 25.990 & 25.050 & 28.020 & 1.030 & 0.145 & $<0.0001$ & 0.812 & 0.730 & 0.063 \\
\hline $\mathrm{LDL}, \mathrm{mg} \cdot \mathrm{dL}^{-1}$ & 46.020 & 44.510 & 44.910 & 1.550 & 0.773 & $<0.0001$ & 0.083 & 0.540 & 0.861 \\
\hline VLDL, mg.dL ${ }^{-1}$ & 7.200 & 7.520 & 6.690 & 0.560 & 0.595 & $<0.0001$ & 0.782 & 0.857 & 0.337 \\
\hline
\end{tabular}

189 aSows, fed with a Control milk (Control), supplemented with cow's milk enriched with n-3 or n-6.

190 bSEM, standard error of the mean.

$191{ }^{\mathrm{C}} \mathrm{C} 1$, contrast Control vs n-3+n-6; C2, contrast n-3 vs n-6. 
192

\section{Hemogram and leukogram}

Control gilts had reduced red blood cells (RBC), platelets, and lymphocytes compared to those that received enriched cow's milk $(\mathrm{P}<0.10$, Table 6$)$. Besides, these females had lower leukocytes $(P=0.049$, Table 6$)$ and higher monocytes $(P=0.041$, Table 6$)$ than the gilts of the omega group. These females also had increased mean corpuscular hemoglobin (MCH) compared to those of the omega group $(\mathrm{P}=0.070$, Table 6$)$. The other counts were not affected by milk supplementation $(\mathrm{P}>0.05$, Table 6$)$. 
199 Table 6. Hemogram and leukogram of the control, n-3, and n-6 groups of gilts supplemented from 34 to 190 days old

\begin{tabular}{|c|c|c|c|c|c|c|c|c|c|}
\hline \multirow{2}{*}{ Item $^{a}$} & \multicolumn{3}{|c|}{ Treatments $^{b}$} & \multirow{2}{*}{$\mathrm{SEM}^{c}$} & \multicolumn{5}{|c|}{ P-value } \\
\hline & Control & $n-3$ & $n-6$ & & Treatment & Time & Treat*Time & $\mathrm{C}^{\mathrm{d}}$ & $\mathrm{C} 2^{\mathrm{d}}$ \\
\hline \multicolumn{10}{|l|}{ Hemogram } \\
\hline $\mathrm{RBC}, 10^{6} . \mathrm{mm}^{-3}$ & 7.188 & 7.465 & 7.484 & 0.118 & 0.149 & $<0.0001$ & 0.127 & 0.053 & 0.908 \\
\hline Hemoglobin, g. $\mathrm{dl}^{-1}$ & 12.248 & 12.298 & 12.297 & 0.148 & 0.963 & $<0.0001$ & 0.163 & 0.786 & 0.999 \\
\hline Hematocrit, \% & 40.182 & 40.423 & 40.808 & 0.580 & 0.750 & $<0.0001$ & 0.111 & 0.543 & 0.642 \\
\hline $\mathrm{MCV}, \mathrm{fl}$ & 55.984 & 54.222 & 54.602 & 0.830 & 0.283 & 0.6070 & 0.366 & 0.125 & 0.748 \\
\hline $\mathrm{MCH}, \mathrm{pg}$ & 17.045 & 16.472 & 16.448 & 0.255 & 0.188 & $<0.0001$ & 0.622 & 0.070 & 0.948 \\
\hline $\mathrm{MCHC}, \%$ & 30.484 & 30.416 & 30.126 & 0.155 & 0.246 & $<0.0001$ & 0.313 & 0.264 & 0.198 \\
\hline Platelets, $\times 10^{5} \cdot \mathrm{mm}^{-3}$ & 2.673 & 3.202 & 3.028 & 18.950 & 0.140 & $<0.0001$ & 0.674 & 0.064 & 0.521 \\
\hline \multicolumn{10}{|l|}{ Leukogram } \\
\hline Leukocytes, $\times 10^{3} \cdot \mathrm{mm}^{-3}$ & 12.78 & 14.20 & 14.47 & 0.650 & 0.137 & $<0.0001$ & 0.918 & 0.049 & 0.766 \\
\hline Segmented, $\times 10^{3} \cdot \mathrm{mm}^{-3}$ & 5.11 & 5.62 & 4.96 & 1.061 & 0.302 & 0.0026 & 0.972 & 0.665 & 0.147 \\
\hline Lymphocytes, $\mathrm{x} 10^{3} \cdot \mathrm{mm}^{-3}$ & 6.33 & 7.07 & 7.91 & 1.078 & 0.139 & $<0.0001$ & 0.732 & 0.089 & 0.294 \\
\hline Monocytes, $\mathrm{x} 10^{3} \cdot \mathrm{mm}^{-3}$ & 1.07 & 0.80 & 0.84 & 1.218 & 0.517 & 0.0184 & 0.736 & 0.257 & 0.890 \\
\hline Eosinophils, $\mathrm{x} 10^{3} \cdot \mathrm{mm}^{-3}$ & 0.32 & 0.23 & 0.33 & 1.250 & 0.488 & $<0.0001$ & 0.918 & 0.553 & 0.281 \\
\hline
\end{tabular}

201 bSows fed with a Control milk (Control), supplemented with cow's milk enriched with n-3 or n-6.

202 'SEM, standard error of the mean.

$203{ }^{\mathrm{d}} \mathrm{C} 1$, contrast Control vs n-3+n-6; C2, contrast n-3 vs n-6. 
Polyunsaturated fatty acids are essential for normal physiological function and the

health of humans and domestic animals. Considering the opposing effects of $n-3$ and $n-6$

PUFA, the proportion of these PUFA, especially dietary linoleic acid and $\alpha$-linolenic acid, may

regulate diverse sets of homeostatic processes by themselves or by locally acting bioactive signaling lipids called eicosanoids derived from arachidonic acid, eicosapentaenoic acid, and docosahexaenoic acid [22]. polyunsaturated fatty acids n-6 and n-3 to reduce it [23]. The supplementation of gilts with cow's milk enriched naturally with PUFA from 34 to 190 days old led to changes in fatty acid profile and leukogram, as well as a trend was observed for increase HDL and reduce LDL, and hemogram; however, the growth performance had been similar among the females' groups. pigs, fed diets in different n-6: n-3 ratios $(15.17,9.68$, and 4.87, high, medium, and lower, respectively). Nevertheless, in blood lipids, a reduction in total cholesterol, LDL, and triglycerides were observed for the lower ratio n-6:n-3 PUFA compared to animals in the other groups. Similarly, Li et al. [25] reported based on a meta-analysis in humans that low-ratio n6/n-3 PUFA reduced triglyceride concentration and increased HDL concentration $(\mathrm{P}<0.05)$, and the beneficial effects of low-ratio n-6/n-3 PUFA on blood lipids were enhanced with time. Besides these, researchers also verified that n-3 PUFA derived from plants significantly reduced total cholesterol and LDL concentrations, and n-3 PUFA derived from eicosapentaenoic acid (EPA) and DHA significantly reduced triglyceride concentration and increased HDL concentration.

In the present study, different n-6:n-3 PUFA ratios were observed in cow's milk enriched with n-3 and n-6 sources (2.72, 7.92 and 8.26, n-3, group control, and n-6, respectively), but in female serum, the ratio was similar $(16.35,27.27$ and 25.53 , n-3, control group, and n-6, respectively) after 22 weeks of supplementation. Growth performance results 
232 were similar to those reported by Liu and Kim [24]. On the other hand, HDL trended an

233 increase in the n-6 group compared with n-3, and total cholesterol was similar among the group.

234 Considering the overall period, the LDL was numerically lower in animals from the n-3 and n-6

235 groups, but a trend towards the difference between the PUFA groups was observed at 77 and 190 days old. An increase in LDL concentration from 34 to 77 days was verified in three groups, but from that moment on, the animals in the $n-6$ group had a reduction while the other groups remained elevated. Several factors may influence these results, such as the presence or absence of lipoprotein disorders, the relation between VLDL and total cholesterol, the dose of oil administered, varying effects of EPA vs. DHA, the source of $n-3$, the type of individual the study is being conducted on (normolipidemic or hypercholesterolemic), and the period of supplementation [26,27].

The importance of lipids consumed in the diet on the effects on human health has been widely discussed, as they influence the lipid composition of blood, colostrum, milk, tissues, and it is even possible to observe the manipulation of gene expression and immunity [28-30]. Myristic and stearic acids are the most abundant saturated fatty acids in mammals [31]. Myristic acid has from 8 to $12 \%$ of total fat milk, and a more substantial intake of this lipid raises LDL concentrations [32].

Cow's milk from the study by [13] was supplemented for gilts in this current study, and this milk had a lower concentration of myristic acid than those without the oil supplementation (7.59, 7.98, and 10.36, soybean, linseed, and control, respectively, $\mathrm{P}<0.05$ ), as well as reduction of SFA $(56.52,56.69$ and 66.89 , soybean, linseed, and control, respectively, $\mathrm{P}<0.05)$. This fact may have directly influenced the serum fatty acid profile of gilts of n-3 and n6 groups. Besides, myristic acid may be produced through de novo lipogenesis, but it represents a small fraction [33]. Thus, we believe that the alteration found in the blood myristic acid may have come directly from the lipids present in milk through the transfer from the small intestine by diffusion or facilitated transport. 
control, respectively, $\mathrm{P}<0.05)$, and no differences between the PUFA-supplemented groups responsible for the biosynthesis of oleic acid (18:1) by desaturating stearic acid (18:0) [35-37].

The length, structure, and number of double bonds in the fatty acid chains also seem to influence the activity of SCD, according to [38]. The linoleic acid and EPA can directly regulate SCD activity at the level of transcription via sterol regulatory element-binding protein 1c (SREBP-1c), but the same does not occur with $\alpha$-linolenic acid (ALA) [39]. Therefore, the difference in stearic acid found between $n-3$ and n- 6 groups may have been influenced by all these factors, since cow's milk enriched with soy oil had a higher concentration of linoleic acid $(2.13,2.62$ and 2.03, control, soybean, and linseed, respectively [13].

In the present study, control gilts tended to have a reduced $\mathrm{RBC}$, platelets, and lymphocytes and enhanced $\mathrm{MCH}$ compared to those that received enriched cow's milk. These females also had lower leukocytes and higher monocytes than the gilts of the PUFA group. injury or infection. Thus, several cells are moved towards the affected site, including leukocytes, which can be modulated by fatty acids. This is because leukocytes have an important role in inflammation and infection, through the synthesis of important cytokines, some with more inflammatory functions, arising from PUFA n-6, and others with more antiinflammatory functions, mainly from PUFA n-3 [40,41]. In this case, the $n-6$ PUFA is a substrate for the synthesis of eicosanoids, such as prostaglandins (PGs), thromboxanes (TXs), leukotrienes (LTs), and hydroxyeicosatetraenoic acids (HETEs). Among the series 4 LTs are: $\mathrm{LTA}_{4}, \mathrm{~B}_{4}, \mathrm{C}_{4}, \mathrm{D}_{4}$ and $\mathrm{E}_{4}$, and $\mathrm{LTB}_{4}$ is a potent chemotactic agent for leukocytes [40]. 
287 perform in the body in terms of cytokine production, cell proliferation, adhesion molecules, and 288 cell death.

The consumption of PUFA can cause different effects on the cells that make up the blood plasma. According to Xia et al. [42], dietary n-3 polyunsaturated fatty acids (fish oil) in mice alters the hematopoietic microenvironment and induces the expression of matrix metalloproteinase 12 (MMP12) in stromal cells, providing new insights into diet-mediated regulation of hematopoiesis. Similar results were found by [43], in which oral administration of PUFA in mice increases hematopoiesis in them by generating active metabolites, which activate the Wnt and CXC Chemokine Receptor Type 4 (CXCR4) pathways and promote thrombopoiesis through the Notch proteins (Notch1) pathway. Although, how the dietary fatty acids can influence the hematopoiesis remains yet largely unclear. Unlike the aforementioned results, except for the segmented ones, the other variables related to hematopoiesis had similar results between groups n-3 and n-6, without the effect of n-3 PUFA in our study.

The increased intake of EPA and DHA replaces the arachidonic acid in the cell membranes of erythrocytes, platelets, neutrophils, monocytes, and liver cells [44] and according to [45] and [46] as a consequence may occur: 1) reduced prostaglandin (PG) synthesis of series $2 ; 2)$ reduction of thromboxane A2 (TXA2), which acts by aggregating platelets and causes vasoconstriction; 3) reduced production of leukotrienes B4, which induces inflammation; 4) increased of thromboxane A3 (TXA3), which are weak as platelet aggregators and as vasoconstrictors; 5) higher synthesis of prostaglandin I3 (PGI3) without reducing PGI2, which act as active vasodilators and inhibitors of platelet aggregation; 6) higher concentrations of LT of type B5, which is a chemotactic agent and a weak inducer of inflammation. response, although their proliferation may be impaired due to $\gamma$-linolenic acid or EPA $[47,48]$. Caughey et al. [49] suggest a reduction in the function of immune cells after supplementing

312 humans with a high concentration of n-3 PUFA (linseed oil) due to reduced synthesis of interleukin-1 and tumor necrosis factor (TNF) by blood monocytes. 
Ingestion of PUFA leads to their distribution to virtually every cell in the body,

resulting in effects on membrane composition and function, cellular signaling, and regulation of

growing were not expressive in the current study, more studies are necessary to clarify how the animals e humans.

In conclusion, gilt that received the cow's milk enriched naturally with PUFA n-3 or n-6

had similar growth performance, but the blood fatty acid profile and hematological parameters were altered without impairing the health of gilts. This study provided insight concerning how food enriched can modulate the serum lipid profile and cells of the defense system, promoting health benefits.

\section{ACKNOWLEDGEMENTS}

The authors would like to thank the São Paulo Research Foundation (FAPESP) by the financial support (Grant n 2015/19393-8) and Coordenação de Aperfeiçoamento de Pessoal de Nível Superior - Brasil (CAPES) - Finance Code 001.

The authors' contributions are as follows: A. S. N. designed the study and was the principal investigator who supervised all aspects of the study. A. S. N. and A. F. C. d. A. conceptualized the study. L. G. R. conducted the animal study and wrote the manuscript as part of her postgraduate studies. T. H. S. realized the statistical analysis. S. M. M. K. M. critically reviewed the manuscript. L. G. R., T. H. S., S. M. M. K. M., M. S. V. S. and P. L. T. did data curation. All the authors read, edited, and approved the final manuscript. 


\section{REFERENCES}

1. Rancourt-Bouchard M, Gigleux I, Guay V, Charest A, Saint-Gelais D, Vuillemard JC, et al. Effects of regular-fat and low-fat dairy consumption on daytime ambulatory blood pressure and other cardiometabolic risk factors: A randomized controlled feeding trial. Am J Clin Nutr. 2020;111: 42-51. doi:10.1093/ajcn/nqz251

2. Silva ARA, Silva MMN, Ribeiro BD. Health issues and technological aspects of plantbased alternative milk. Food Res Int. 2020;131: 108972.

doi:10.1016/j.foodres.2019.108972

3. Chilliard Y, Ferlay A. Dietary lipids and forages interactions on cow and goat milk fatty acid composition and sensory properties. Reprod Nutr Dev. 2004;44: 467-492.

4. Gómez-Cortés P, Cívico A, de la Fuente MA, Núñez Sánchez N, Juárez M, Peña Blanco F, et al. Quick changes of milk fatty acids after inclusion or suppression of linseed oil in the diet of goats. J Sci Food Agric. 2018;98: 5269-5277. doi:10.1002/jsfa.9065

5. Liu B, Jiang J, Yu D, Lin G, Xiong LY. Effects of Supplementation of Microalgae (Aurantiochytrium sp.) to Laying Hen Diets on Fatty Acid Content, Health Lipid Indices, Oxidative Stability, and Quality Attributes of Meat. Foods. 2020;9. doi:10.3390/foods 9091271

6. Nong Q, Wang L, Zhou Y, Sun Y, Chen W, Xie J, et al. Low dietary N-6/N-3 Pufa ratio regulates meat quality, reduces triglyceride content, and improves fatty acid composition of meat in Heigai pigs. Animals. 2020;10: 1-14. doi:10.3390/ani10091543

7. Parodi PW. Has the association between saturated fatty acids, serum cholesterol and coronary heart disease been over emphasized? Int Dairy J. 2009;19: 345-361. doi:10.1016/j.idairyj.2009.01.001

8. Paszczyk B, Luczyńska J. The Comparison of Fatty Acid Composition and Lipid Quality Indices in Hard Cow, Sheep, and Goat Cheeses. Foods. 2020;9: 1667. doi:10.3390/foods9111667

9. Ulbricht TL V., Southgate DAT. Coronary heart disease and dietary factors. Lancet. 1992;339: 987-988. doi:10.1016/0140-6736(92)91558-P 
10. Castellani F, Vitali A, Bernardi N, Marone E, Palazzo F, Grotta L, et al. Dietary supplementation with dried olive pomace in dairy cows modifies the composition of fatty acids and the aromatic profile in milk and related cheese. J Dairy Sci. 2017;100: 8658-8669. doi:10.3168/jds.2017-12899

11. O'Connell TD, Block RC, Huang SP, Shearer GC. $\omega 3$-Polyunsaturated fatty acids for heart failure: Effects of dose on efficacy and novel signaling through free fatty acid receptor 4. J Mol Cell Cardiol. 2017;103: 74-92. doi:10.1016/j.yjmcc.2016.12.003

12. Welter KC, de Magalhães Rodrigues Martins CM, de Palma ASV, Martins MM, dos Reis BR, Schmidt BLU, et al. Canola oil in lactating dairy cow diets reduces milk saturated fatty acids and improves its omega-3 and oleic fatty acid content. PLoS One. 2016;11: 1-16. doi:10.1371/journal.pone.0151876

13. Oliveira MXS, Palma ASV, Reis BR, Franco CSR, Marconi APS, Shiozaki FA, et al. Inclusion of soybean and linseed oils in the diet of lactating dairy cows makes the milk fatty acid profile nutritionally healthier for the human diet. PLoS One. 2021;16: 1-19. doi:10.1371/journal.pone.0246357

14. Yoshimura EH, Santos NW, MacHado E, Agustinho BC, Pereira LM, De Aguiar SC, et al. Functionality of cow milk naturally enriched with polyunsaturated fatty acids and polyphenols in diets for diabetic rats. PLoS One. 2018;13: 2-13. doi:10.1371/journal.pone.0195839

15. Reis LG, da Silva TH, Ravagnani GM, Martinez CHG, Salles MSV, de Andrade AFC, et al. Maternal supplementation with cow's milk naturally enriched with pufa alters the metabolism of sows and the fatty acid profile of the offspring. Nutrients. 2021;13. doi:10.3390/nu13061942

16. Guilloteau P, Zabielski R, Hammon HM, Metges CC. Nutritional programming of gastrointestinal tract development. Is the pig a good model for man? Nutr Res Rev. 2010;23: 4-22. doi:10.1017/S0954422410000077

17. Bendixen E, Danielsen M, Larsen K, Bendixen C. Advances in porcine genomics and proteomicsc-a toolbox for developing the pig as a model organism for molecular 
biomedical research. Briefings Funct Genomics Proteomics. 2010;9: 208-219.

doi:10.1093/bfgp/elq004

18. Rostagno HS, Albino LFT, Hannas MI, Donzele JL, Sakomura NK, Perazzo FG, et al.

Tabelas brasileiras para aves e suínos: composição de alimentos e exigências

nutricionais. 4th ed. Viçosa: Universidade Federal de Viçosa; 2017.

19. Brazilian Ministry of Health. Feeding Guide for the Brazilian Population: Promoting the Health Food. 2008 p. 210. doi:978-85-334-2176-9

20. Huang Z, Wang B, Crenshaw AA. A simple method for the analysis of trans fatty acid with GC-MS and AT ${ }^{\text {TM}}-$ Silar-90 capillary column. Food Chem. 2006;98: 593-598. doi:10.1016/j.foodchem.2005.05.013

21. Friedewald WT, Levy RI, Fredrickson DS. Estimation of the concentration of lowdensity lipoprotein cholesterol in plasma, without use of the preparative ultracentrifuge. Clin Chem. 1972;18: 499-502. Available:

http://www.ncbi.nlm.nih.gov/pubmed/4337382

22. Dennis EA and PCN. Eicosanoid stomrm in in. Nat Rev Immunol. 2015;11: 511-523. doi:10.1038/nri3859.Eicosanoid

23. MARZZOCO, A.; TORRES, BB. Bioquímica básica. 3. ed. Rio de Janeiro: Guanabara Koogan, 2015.

24. Liu WC, Kim IH. Effects of different dietary n-6:n-3 PUFA ratios on growth performance, blood lipid profiles, fatty acid composition of pork, carcass traits and meat quality in finishing pigs. Ann Anim Sci. 2018;18: 143-154. doi:10.1515/aoas-2017-0026

25. Li N, Jia M, Deng Q, Wang Z, Huang F, Hou H, et al. Effect of low-ratio n-6/n-3 PUFA on blood lipid level: a meta-analysis. Hormones. 2020. doi:10.1007/s42000-020-00248-0

26. Dyerberg J. Linolenate-derived Polyunsaturated Fatty Acids and Prevention of Atherosclerosis. Nutr Rev. 1986;44: 125-134. doi:10.1111/j.1753-4887.1986.tb07603.x

27. Dyerberg J, Jørgensen KA. Marine oils and thrombogenesis. Prog Lipid Res. 1982;21: 255-269. doi:10.1016/0163-7827(82)90011-X

28. Chen XL, Wang N, Tian ML, Wang L, Liu T, Zhang XW, et al. Dietary linseed oil in the 
maternal diet affects immunoglobulins, tissue fatty acid composition and expression of lipid metabolism-related genes in piglets. J Anim Physiol Anim Nutr (Berl). 2016;101: e257-e265. doi:10.1111/jpn.12599

29. Missotten J, De Smet S, Raes K, Doran O. Effect of supplementation of the maternal diet with fish oil or linseed oil on fatty-acid composition and expression of $\Delta 5$ - and $\Delta 6$ desaturase in tissues of female piglets. animal. 2009;3: 1196-1204. doi:10.1017/S1751731109004455

30. Rooke JA, Bland IM, Edwards SA. Effect of feeding tuna oil or soyabean oil as supplements to sows in late pregnancy on piglet tissue composition and viability. Br J Nutr. 1998;80: 273-280. doi:10.1017/S0007114598001329

31. Dukes HH. Fisioligia dos animais domésticos. 12. ed. Rio de Janeiro: Guanabara Koogan; 2006. 926p.

32. Kohlmeier M. Fatty Acids. Nutrient Metabolism: Structures, Functions, and Genes. Chapel Hill: Academic Press; 2015. pp. 111-186. doi:10.1016/B978-0-12-387784$0.00005-5$

33. Hellerstein MK. No common energy currency: De novo lipogenesis as the road less traveled. Am J Clin Nutr. 2001;74: 707-708. doi:10.1093/ajcn/74.6.707

34. Bellenger J, Bellenger S, Clément L, Mandard S, Diot C, Poisson JP, et al. A new hypotensive polyunsaturated fatty acid dietary combination regulates oleic acid accumulation by suppression of stearoyl CoA desaturase 1 gene expression in the SHR model of genetic hypertension. FASEB J. 2004;18: 773-775. doi:10.1096/fj.03-0950fje

35. Paton CM, Ntambi JM. Biochemical and physiological function of stearoyl-CoA desaturase. Am J Physiol - Endocrinol Metab. 2009;297: 28-37. doi:10.1152/ajpendo.90897.2008

36. Estany J, Ros-Freixedes R, Tor M, Pena RN. A functional variant in the stearoyl-CoA desaturase gene promoter enhances fatty acid desaturation in pork. PLoS One. 2014;9: 1-11. doi:10.1371/journal.pone.0086177

37. Smith SB, Smith DR. Fats: Production and Uses of Animal Fats. 1st ed. Encyclopedia of 
Food and Health. Elsevier Ltd.; 2016. doi:10.1016/B978-0-12-384947-2.00273-7

38. Ntambi JM. The regulation of stearoyl-CoA desaturase (SCD). Prog Lipid Res. 1995;34: 139-150. doi:10.1016/0163-7827(94)00010-J

39. Velliquette RA, Gillies PJ, Kris-Etherton PM, Green JW, Zhao G, Vanden Heuvel JP. Regulation of human stearoyl-CoA desaturase by omega- 3 and omega- 6 fatty acids: Implications for the dietary management of elevated serum triglycerides. J Clin Lipidol. 2009;3: 281-288. doi:10.1016/j.jacl.2009.06.002

40. Calder PC. Polyunsaturated fatty acids and inflammation. Prostaglandins Leukot Essent Fat Acids. 2006;75: 197-202. doi:10.1016/j.plefa.2006.05.012

41. Pompéia C, Lopes LR, Miyasaka CK, Procópio J, Sannomiya P, Curi R. Effect of fatty acids on leukocyte function. Brazilian J Med Biol Res. 2000;33: 1255-1268. doi:10.1590/S0100-879X2000001100001

42. Xia S, Li XP, Cheng L, Han MT, Zhang MM, Shao QX, et al. Fish oil-rich diet promotes hematopoiesis and alters hematopoietic niche. Endocrinology. 2015;156: 2821-2830. doi:10.1210/en.2015-1258

43. Limbkar K, Dhenge A, Jadhav DD, Thulasiram H V., Kale V, Limaye L. Oral feeding with polyunsaturated fatty acids fosters hematopoiesis and thrombopoiesis in healthy and bone marrow-transplanted mice. Journal of Nutritional Biochemistry. Elsevier Inc.; 2017. doi:10.1016/j.jnutbio.2017.05.002

44. Simopoulos AP. The Mediterranean Diets in Health and Disease. Am J Clin Nutr. 1991;54: 771-771. doi:10.1093/ajen/54.4.771

45. Lewis RA, Lee TH, Austen KF. Effects of omega-3 fatty acids on the generation of products of the 5-lipoxygenase pathway. Health Effects of Polyunsaturated Fatty Acids in Seafoods. ACADEMIC PRESS, INC.; 1986. doi:10.1016/b978-0-12-644360-8.500169

46. Weber PC, Fischer S, Schacky C von, Lorenz R, Strasser T. Dietary Omega-3 Polyunsaturated Fatty Acids and Eicosanoid Formation in Man. Health Effects of Polyunsaturated Fatty Acids in Seafoods. ACADEMIC PRESS, INC.; 1986. 
doi:10.1016/b978-0-12-644360-8.50007-8

47. Healy DA, Wallace FA, Miles EA, Calder PC, Newsholme P. Effect of low-to-moderate amounts of dietary fish oil on neutrophil lipid composition and function. Lipids.

2000;35: 763-768. doi:10.1007/s11745-000-0583-1

48. Thies F, Nebe-Von-Caron G, Powell JR, Yaqoob P, Newsholme EA, Calder PC. Dietary supplementation with $\gamma$-linolenic acid or fish oil decreases $t$ lymphocyte proliferation in healthy older humans. J Nutr. 2001;131: 1918-1927. doi:10.1093/jn/131.7.1918

49. Caughey GE, Mantzioris E, Gibson RA, Cleland LG, James MJ. The effect on human tumor necrosis factor $\alpha$ and interleukin $1 \beta$ production of diets enriched in $n-3$ fatty acids from vegetable oil or fish oil. Am J Clin Nutr. 1996;63: 116-122.

doi:10.1093/ajen/63.1.116 


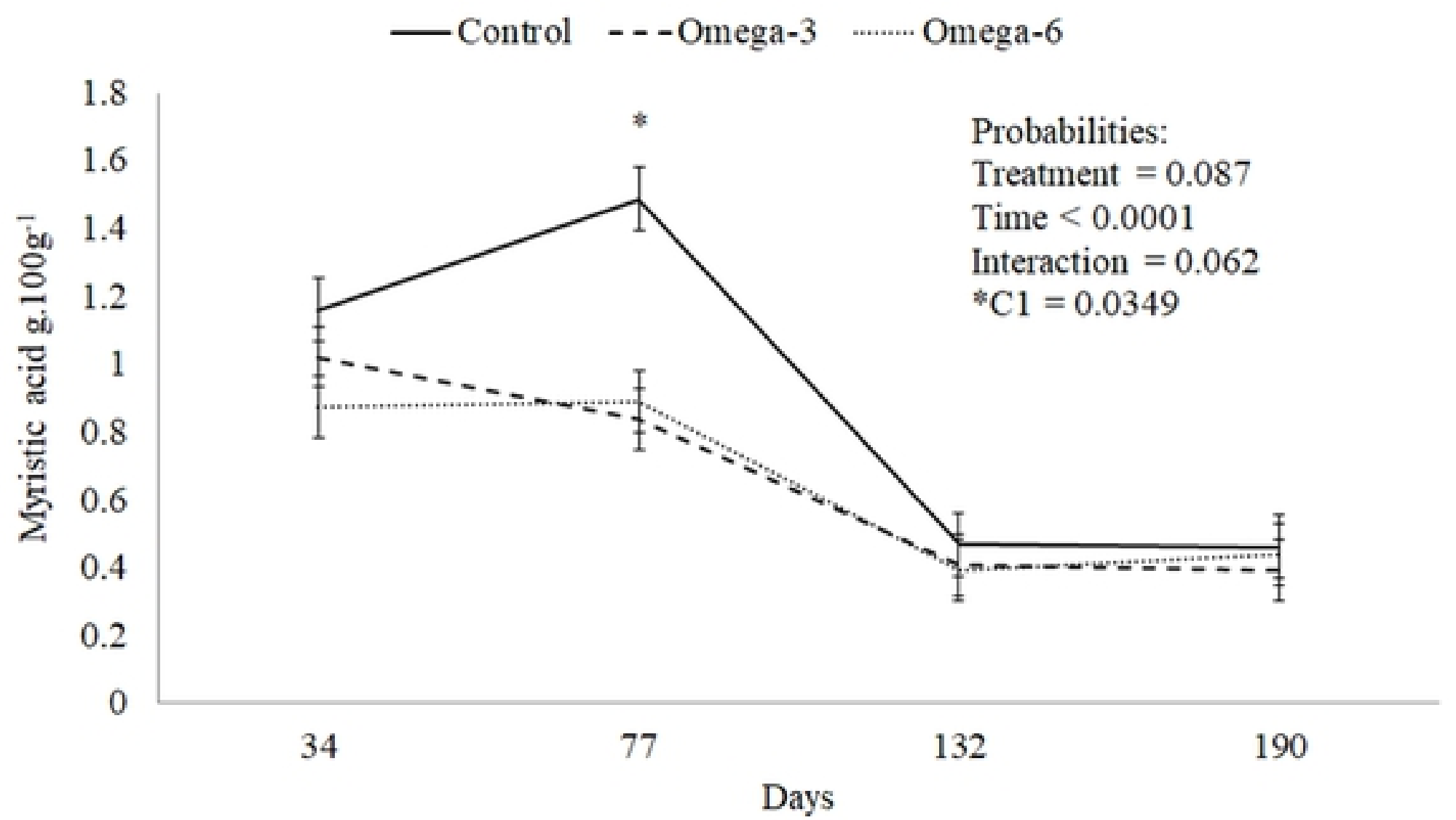

Figure 1 


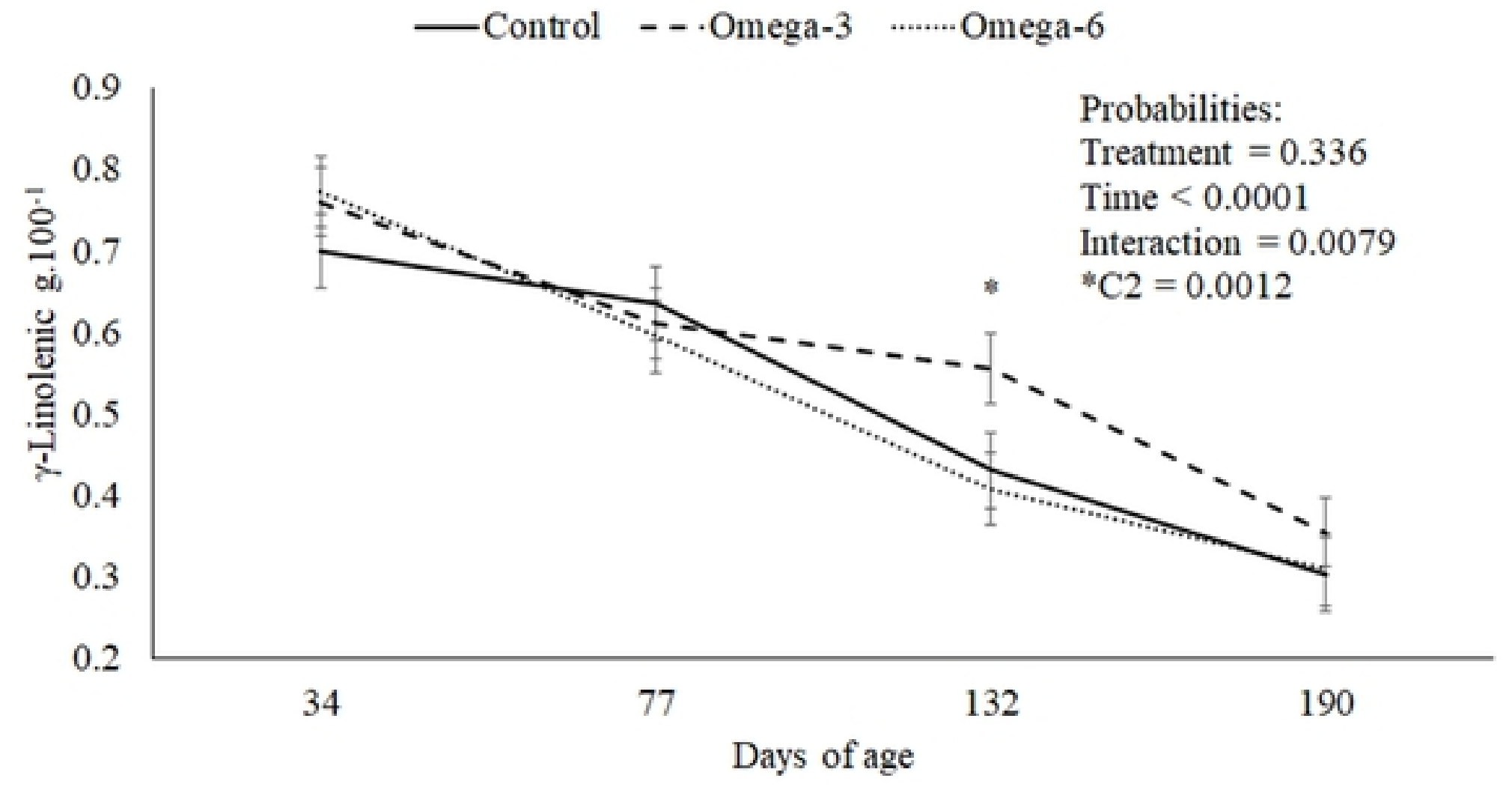

Figure 2 


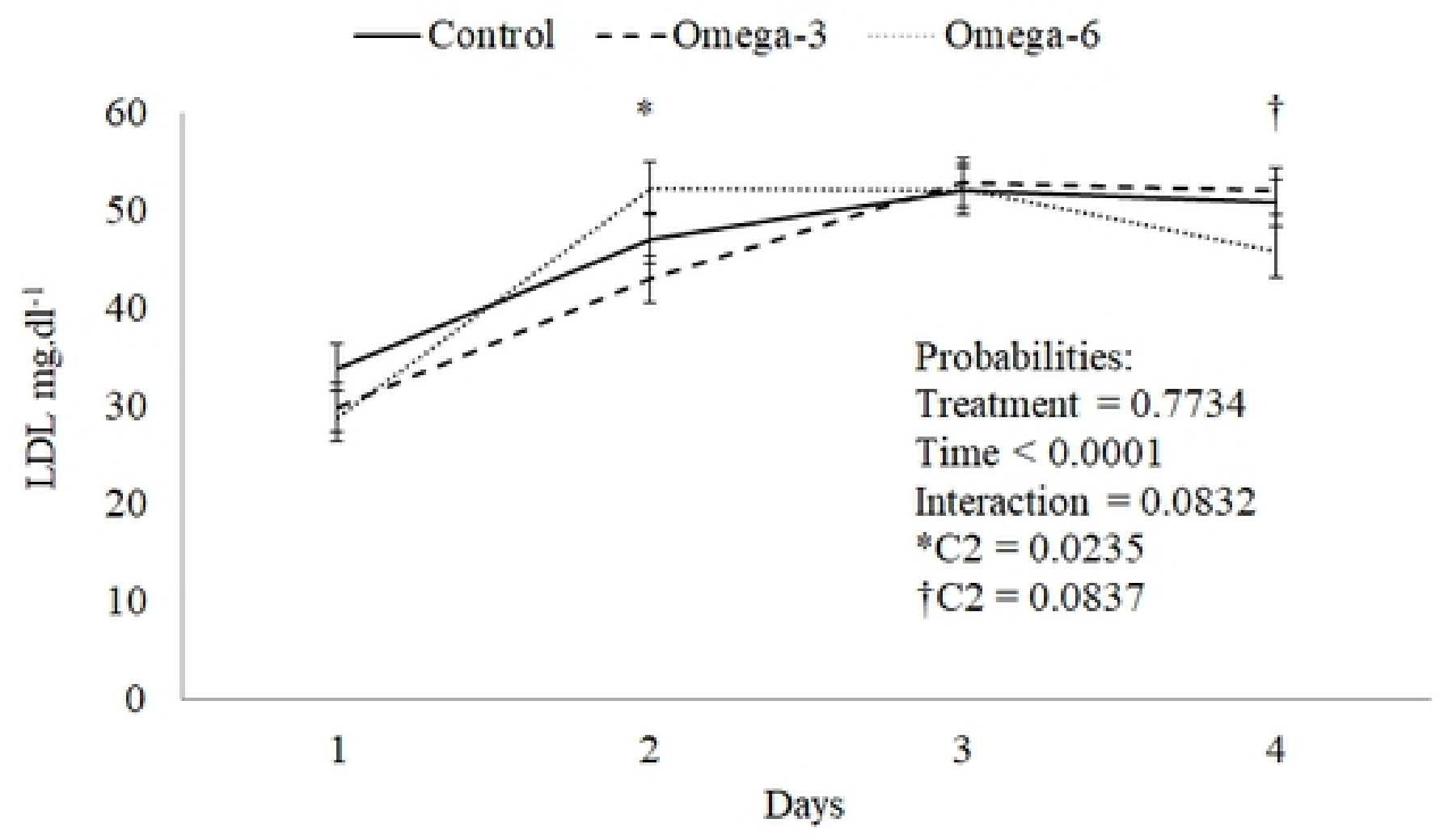

Figure 3 